\title{
FORMALISME KEHIDUPAN BERAGAMA (Studi Kasus Gereja Katolik Keuskupan Purwokerto)
}

\author{
Robertus Suraji*
}

\begin{abstract}
Indonesia is a nation that seems religious. Place of worship was flooded with a lot of people. Events and holy days of religius became a national event. In the other hand, some times the religious comprehention was halted at the places of worship that was it. In the national and society life easily we can find people to do things that are contrary to religious values. Human rights violations and corruption becomes difficult to eradicate. Moral degradation occurs from the level of family, community, society and state officials. Within communities also repeatedly occurred certain group use religion as an instrument of legitimacy to the acts of violence driven by a belief in their own truth as the only truth, and the loss of a sense of respect for those who are considered different. Hence people are not so concerned with the behavior that is contrary to what religion had been teaches, even assume it was not related to faith. On the other hand there are people who are aware of the true situation but are powerless, or do not have enough courage to reject it. This is the situation called formalism of Religious Life. The cause of religious formalism that may arise from the internal religious teachings, not only from the social structure of society but also of a culture that is built in this community. The impact of these religious formalism can happen on a personal level, both the social structure and the culture of the society. Therefore, to counter religious formalism is not enough left to religious leaders, but also there should be a joint motion to change the structure and culture of Indonesian society.
\end{abstract}

Kata-kata Kunci: Formalisme agama, struktur masyarakat, ajaran agama, kultur.

\section{LATAR BELAKANG}

Dunia sekarang ini ditandai dengan berkembangnya teknologi komunikasi yang sangat cepat. Situasi ini pantas disyukuri karena memungkinkan kita untuk berkomunikasi dengan lebih cepat dan lebih

* Robertus Suraji, Doktor dalam Bidang Agama dan Budaya; lulusan Universitas Gajdah madha, Yogyakarta; Dosen di Sekolah Tinggi Ilmu Komputer Yos Sudarso, Purwokerto. 
mudah. Informasi berbagai hal, bahkan hiburan dapat kita peroleh dengan mudah. Akan tetapi disamping nilai positif yang kita peroleh, kita sadari pula ada akibat-akibat negatif yang ditimbulkan oleh perkembangan teknologi tersebut. Dalam dunia yang semakin terbuka oleh teknologi komunikasi tersebut kontrol terhadap nilai-nilai kehidupan ditentukan oleh mereka yang menguasai teknologi. Berbagai kearifan lokal yang mendukung kehidupan tergeser oleh fungsi teknologi komunikasi karena memudarnya dukungan terhadap lokalitas. Hidup orang menjadi sangat pragmatis. Materialisme sangat menguasai kehidupan orang.

Bangsa Indonesia adalah bangsa yang nampak religius. Tempattempat ibadah biasa dibanjiri banyak orang. Acara-acara dan hari-hari besar keagamaan menjadi acara nasional. Namun demikian, seringkali penghayatan keagamaan itu terhenti di tempat-tempat ibadah itu saja. Dalam kehidupan berbangsa dan bermasyarakat dengan mudah kita dapat menemukan orang melakukan hal-hal yang bertentangan dengan nilai-nilai keagamaan. Pelanggaran kemanusiaan dan korupsi menjadi hal yang sulit sekali diberantas. Kemerosotan moral terjadi mulai dari tingkat keluarga, komunitas, masyarakat dan petinggi negara. Kita juga dapat menyaksikan bagaimana kelompok-kelompok tertentu menggunakan agama sebagai alat legitimasi atas aksi-aksi kekerasan yang didorong oleh keyakinan akan kebenarannya sendiri sebagai satusatunya kebenaran, dan hilangnya rasa penghargaan terhadap pihak yang dianggap berbeda. Seringkali orang tidak begitu peduli dengan perilaku yang bertentangan dengan apa yang diajarkan agama, bahkan mengganggap hal itu tidak berkaitan dengan iman. Di lain pihak ada orang yang menyadari akan situasi yang tidak benar tersebut tetapi tidak berdaya, atau tidak mempunyai cukup keberanian untuk menolak hal tersebut. Ada pula orang (meskipun jumlahnya sangat sedikit) yang karena kesadaran religiusnya berani menanggung kesulitan untuk melawan ketidakbenaran.

Umat Katolik Keuskupan Purwokerto berada dalam alur gerak yang sama dengan umat berkeyakinan lain. Kesadaran religius yang semakin tinggi dimiliki oleh umat Katolik juga. Kesadaran tersebut terungkap dalam iman yang dirayakan dalam upacara liturgi Gereja. Liturgi memang menjadi pusat dan puncak hidup umat Katolik. Iman yang dirayakan dalam liturgi tersebut mestinya terwujud dalam kehidupan harian. Namun kenyataan kehidupan ditemukan bahwa kehidupan umat Katolik tidak selalu mewujudkan iman yang dirayakan tersebut. Hal ini menarik bagi peneliti untuk mengetahui mengapa 
antara penghayatan iman dalam tempat ibadah berbeda dengan perwujutan iman dalam hidup sehari-hari.

\section{MASALAH PENELITIAN}

Mengapa Formalisme Hidup Beragama terjadi di tengah kehidupan masyarakat Purwokerto yang nampak religius?

\section{KERANGKA TEORI}

Kenyataan kehidupan umat beragama seperti terurai dalam latar belakang penelitian ini memperlihatkan hal yang sangat paradoks. Di satu sisi kehidupan peribadatan umat beragama memperlihatkan kekhusukan yang menggambarkan religiusitas yang mendalam, namun dalam kenyataan kehidupan, mereka melakukan hal yang bertentangan dengan kebenaran yang diajarkan oleh agama. Konstruksi sosial telah hadir menjelaskan fenomena tersebut di atas dengan cara melihat realitas sebagai sesuatu yang dibentuk secara sosial. Dalam hal ini konstruksionisme sosial menekankan bahwa bagaimana realitas keadaan dan pengalaman tentang sesuatu diketahui dan diinterpretasi melalui aktifitas sosial. Masyarakat adalah produk manusia dan antara manusia dan masyarakat terjadi proses dialektika.

Dialektika tersebut menurut Berger terjadi demikian:

The fundamenatal dialectic process of society consists of three moment, or steps. Theses are externalization, objectivation, and internalization. Only if these three moments are understood together can an emperically adequate view of society be maintained. Externalization is the ongoing outpouring of human being into the world, both in the physical and mental of men. Objectivation is the attainment by the products of this activity (again both physical and mental) of a reality that confronts its original producers as a facticity externa to and other than themselves. Internalization is the reappropriation by men of this same reality, transforming it once again from structures of the objective world into structures of the subjective consciousness (Berger, 1990: 4). 
Bagi Berger tatanan nilai di dalam kehidupan manusia merupakan hasil proses penghayatan manusia atas hidupnya. Manusia mempunyai kemampuan dan kecenderungan untuk mengaktualisasikan diri. Proses pencurahan diri terus menerus ke dalam dunia hidupnya membentuk tatanan kehidupan melalui aktifitas fisik dan mentalnya itu disebut oleh Berger sebagai eksternalisasi. Sedangkan obyektifikasi adalah proses menjadikan tatanan kehidupan yang dibangun oleh manusia sebagai suatu realitas yang terpisah dengan subyektifitasnya. Dalam hal ini terjadi proses intersubyektif yang dilembagakan atau mengalami proses institusionalisasi. Proses-proses pembiasaan merupakan langkah awal dari pelembagaan atau proses pembudayaan. Tindakan-tindakan berpola yang sudah dijadikan kebiasaan, membentuk lembaga-lembaga yang merupakan milik bersama. Lembaga-lembaga ini mengendalikan dan mengatur perilaku individu (Berger dan Luckmann, 1991:75-78). Internalisasi merupakan proses yang mana nilai-nilai general dan realitas obyektif dipelajari kembali oleh individu dan dijadikan bagian dari hidupnya. Melalui eksternalisasi manusia menciptakan kebudayaan. Sedangkan melalui internalisasi, kebudayaan membentuk manusia.

Dialektika Berger di atas memperlihatkan adanya tiga hal penting dalam hubungannya dengan penghayatan dan perwujutan kehidupan keagamaan di Purwokerto.

\section{Proses eksternalisasi}

Konstruksi sosial selalu terkait dengan ekspresi diri manusia di dalam membangun tatanan kehidupan, atau bisa juga diartikan sebagai proses penyesuaian diri manusia dengan lingkungannya. Sebagai suatu konstruksi sosial, penghayatan dan perwujutan nilai-nilai kebenaran agama terbentuk dari situasi hidup dan selanjutnya diinterpretasikan berdasarkan pengetahuan yang dimilikinya. Lebih jauh Berger mengatakan bahwa proses eksternalisasi merupakan fakta antropologis yang mendasar, dan ini berakar dalam lembaga pengalaman termasuk pengalaman biologis manusia (Berger, 1990:5).

Proses obyektifikasi atau instituasionalisasi atau proses pembudayaan

Nilai-nilai kebenaran dalam realitas sosial dapat ditemukan dalam berbagai basis kebudayaan, seperti lembaga-lembaga sosial, ajaran-ajaran agama, mitos-mitos, simbol-simbol, serta praktek-praktek sosial lainnya. Nilai-nilai budaya ini bersifat obyekif, karena kebudayaan adalah milik publik (bdk. Geertz, 1992: 15). Telah disebutkan di atas bahwa tindakan-tindakan berpola yang sudah 
dijadikan kebiasaan membentuk lembaga yang merupakan milik bersama, dan akhirnya lembaga-lembaga tersebut mengatur perilaku individu (Berger, 1990: 17). Masalahnya adalah nilai-nilai tersebut tidak netral melainkan menurut kepentingan pihak-pihak yang berkuasa pada saat pembentukannya.

\section{Proses internalisasi}

Internalisasi adalah proses penyerapan nilai-nilai general atau obyektif oleh individu dan menjadikannya sebagai bagian dari hidupnya. Hal ini menyangkut identifikasi individu ke dalam realitas obyektif. Untuk mencapai taraf ini individu secara terus-menerus berinteraksi dan bersosialisasi dengan lingkungan sosial dan budayanya, sehingga akhinya seorang pribadi terbentuk dengan suatu identitas yang dikenal dengan cara subyektif sekaligus obyektif (Berger, 1990: 23). Nilai-nilai kebenaran agama yang dihayati oleh individu maupun komunitas akan terbatinkan (terinternalisasi) dan menjadi bagian hidup secara individu.

Sidang Agung Gereja Katolik Indonesia (SAGKI) 2005 merumuskan bahwa Formalisme Agama menunjuk kepada penghayatan agama yang bersifat formalis dan legalis sehingga dalam hidup keseharian kurang dihayati sebagai nilai dan sikap hidup pribadi maupun kelompok. Penghayatan hidup keagamaan di Indonesia ini ternyata seringkali terwujud dalam bentuk-bentuk kesalehan semu. Akibatnya ialah, bahwa potensi pembebasan yang terkandung dalam setiap agama belum dapat diwujutnyatakan secara maksimal.

Tiga faktor penyebab:

Pertama, Pemahaman yang keliru tentang hubungan antara agama dengan dan dalam Negara demokrasi Indonesia. Pemahaman yang keliru tersebut menyebabkan bahwa seringkali orang memaksakan keyakinan pribadinya kepada masyarakat dan kalau perlu memakai atau memaksa Negara atau pemerintah sebagai alat untuk itu. Sebaliknya juga terjadi Negara atau pengelola bisnislah yang memanfaatkan sentiment keagamaan untuk kepentingan politis dan bisnis.

Kedua, Sikap yang tidak tepat terhadap kenyataan masyarakat yang plural. Hal ini nampak dalam berbagai peristiwa yang menunjukkan bahwa perbedaan belum dimaknai secara positif, melainkan dilihat sebagai ancaman. Kebebasan agama belum sungguh-sungguh terjamin. 
Ketiga, Kedangkalan penghayatan agama. Adanya jurang antara ibadah dan perwujutan iman di dalam masyarakat.

Keprihatinan MUSPAS tentang Formalisme Agama. Musyawarah Umat Katolik Keuskupan Purwokerto (MUSPAS) 2006 menemukan berbagai indikasi yang berkaitan dengan gejala Formalisme Beragama yang hidup dalam diri umat beriman Katolik Keuskupan Purwokerto. MUSPAS merumuskan bahwa Formalisme Agama adalah adanya kesenjangan atau jarak antara nilai-nilai kebenaran yang diajarkan agama dan hidup yang dihayati oleh orang perorangan atau komunitas.

Di dalam definisi di atas terkandung pula pengertian:

Pertama, Penghayatan agama yang bersifat formalis dan legalis, artinya bahwa agama dihayati dalam bentuk-bentuk yang lahiriah saja dan belum sampai membawa kepada penghayatan yang religius.

Kedua, Bentuk-bentuk lahiriah tersebut tidak membawa keterikatan orang kepada yang ilahi, tetapi justru membawa sifat destruktif di dalam hidup bersama.

Ketiga, Dengan demikian agama dalam hidup keseharian kurang dihayati sebagai nilai dan sikap hidup pribadi maupun kelompok.

\section{HASIL PEMBAHASAN}

\section{Faktor penyebab Formalisme Agama}

\section{Agama dan Pengajarannya:}

Adanya paham dualisme dalam pemahaman dan penghayatan keagamaan, yaitu agama dan dunia dilihat sebagai dua hal yang terpisah bahkan bertentangan. Realitas kehidupan ini seringkali dianggap sebagai hal yang tidak berkaitan dengan iman akan Allah atau agama. Ada sekat-sekat di dalam bidang kehidupan yang masing-masing tidak saling berhubungan. Dalam paham yang demikian ini agama diajarkan dan dihayati sebagai sesuatu yang bersifat kultis belaka. Tekanan hidup keagamaan terbatas kepada ritus-ritus peribadatan saja, dan melupakan agama sebagai unsur penggerak kehidupan. Dalam istilah yang berbeda dapat dikatakan bahwa ada jarak antara Altar (pusat peribadatan) dan pasar (kehidupan sehari-hari).

$>\quad$ Penafsiran yang salah terhadap nilai-nilai keagamaan baik oleh pribadi ataupun oleh lembaga agama. Nilai-nilai kebenaran ajaran agama seringkali tidak dipahami secara komprehensif, entah 
karena penafsiran ajaran agama yang literalis (tekstual = berlawanan dengan kontekstual) atau yang terlalu longgar. Dalam kehidupan umat beragama ditemukan bahwa penafsiran salah ini disebabkan oleh pemahaman terhadap kebenaran ajaran iman kurang mendalam.

Ajaran agama tidak terinternalisasi dalam pribadi orang yang memeluk agama. Nilai-nilai kebenaran yang diajarkan oleh agama sebatas pemahaman dan kurang dihayati secara utuh dalam hidup umat beragama, yang mengakibatkan nilai-nilai kebenaran agama tidak menjadi sikap pribadi orang atau kelompok.

\section{Kultur masyarakat:}

> Hilangnya rasa bersalah: Perilaku yang salah ketika dilakukan secara berulang-ulang akan menjadi kebiasaan. Kebiasaan yang dihidupi oleh sekolompok orang akan menjadi budaya. Sesuatu yang telah menjadi budaya kalau pun itu adalah hal yang keliru tidak akan menimbulkan rasa bersalah dalam diri orang yang melakukannya. Kebohongan, ketidakjujuran, korupsi, ketidakadilan, penindasan dan kejahatan moral serta kemanusiaan yang lain tidak disadari lagi sebagai suatu yang salah bahkan dosa karena sudah terbiasa dilakukan.

$>$ Budaya global bagaimana pun ikut memberi sumbangan pada terbentuknya nilai-nilai dalam diri pribadi maupun dalam masyarakat. Dominasi tawaran nilai oleh pasar secara sangat kuat ditawarkan lewat media Televisi, majalah, Koran, internet, dan lain-lain. Suatu wacana yang ditanamkan terus-menerus tanpa sadar akan terinternalisasi (terbatinkan) dalam diri orang dan masyarakat dan menjadi bagian dari sikap hidupnya.

$>$ Agama dihayati sebagai kultur baru yang bertentangan dengan kultur masyarakat. Ketika hidup keagamaan dijauhkan dari budaya masyarakat maka masyarakat tercabut dari akar budayanya. Hidup keagamaan yang demikian menjadi mengering karena bersifat legalis, dan tidak menjadi "agama yang hidup". Agama yang seperti itu bersifat menjajah secara hegemonis dan dapat menghancurkan suatu budaya masyarakat.

\section{Faktor struktur:}

Agama sebagai identitas pribadi: Beragama semestinya merupakan panggilan dan pilihan pribadi setiap orang dengan bebas. Dengan demikian orang akan tergerak untuk menghidupi nilai yang 
diajarkan oleh agama karena dorongan dari dalam dirinya. Kenyataan yang terjadi di Indonesia tidaklah selalu seperti itu. Ketika beragama menjadi suatu kewajiban, maka panggilan itu tidak pernah datang dari diri pribadi orang yang bersangkutan melainkan sebagai kewajiban yang datang dari luar dirinya. Kewajiban mencantumkan kolom agama dalam Kartu Tanda Penduduk (KTP) menyumbang banyak terhadap terjadinya formalisme agama ini.

Agama sebagai lembaga (identitas kelompok): ketika semangat komunalisme mendominasi, penghayatan iman personal dibahayakan maka yang muncul adalah kepentingan kelompok seperti penambahan jumlah, mempertahankan eksistensi dan lainlain. Perang terhadap kelompok lain mudah sekali muncul. Dapat juga terjadi orang mengikuti agama tertentu agar terjamin "keselamatannya" dan kepentingannya oleh kelompok.

Agama dan Negara (politik): mudah sekali terjadi tarik menarik antara kepentingan agama dan politik. Dapat juga terjadi bahwa agama dipakai sebagai legitimasi politik, atau agama memanfaatkan posisi politik anggotanya. Hal yang sama juga dapat terjadi pada relasi agama dan ekonomi. Sistem yang korup membuat orang yang masuk di dalam sistem itu "terpaksa" korup juga.

\section{Dampak dari Formalisme Agama dapat dilihat dalam level:}

\section{Individual:}

Semangat iman kultis: Sering terjadi bahwa antara kehidupan iman dan kehidupan harian ada jarak atau bahkan sekat. Kehidupan dibagi dalam kotak-kotak yang tidak saling berhubungan. Kehidupan iman lepas dari kehidupan harian. Kehidupan iman hanya sebatas tembok gedung gereja. Kehidupan iman tidak boleh dibawa-bawa ke pasar. Akibatnya kehidupan harian sama sekali tidak diresapi oleh semangat (kehidupan) imannya. Iman kultis maksudnya adalah iman merupakan rangkaian ibadat yang harus dipenuhi. Iman yang demikian hanya sekedar obat penenang. Dalam penghayatan yang seperti itu bisa terjadi bahwa orang hidup ibadatnya sangat baik, tetapi kehidupan hariannya sangat brengsek. Ini seolah-olah membenarkan tesis Karl Marx yang menyatakan bahwa agama adalah candu bagi masyarakat. 
Penghayatan iman pragmatis: Gaya hidup atau budaya instant tanpa kita sadari terbawa dalam penghayatan iman. Sering orang pergi beribadah (misalnya pergi ke Gereja) untuk menjadi penikmat liturgi. Artinya ia menuntut bahwa kotbah harus menarik, koor harus bagus, berdoa maunya cepat terkabul, tetapi ia sendiri tidak terlibat apa-apa dalam kehidupan menggereja, tidak bersedia berjuang dan menderita karena penghayatan iman dan keagamaannya.

$>$ Penghayatan iman emosional: Seringkali umat beragama menekankan atribut-atribut dan upacara-upacara keagamaan yang membuatnya merasa menjadi orang yang saleh, meskipun kadang meninggalkan nilai-nilai kemanusiaan. Dalam penghayatan yang menonjolkan identitas keagamaan seperti itu, kalau identitasnya terusik emosi keagamaan mudah muncul. Pertobatan (puasa, pengakuan dosa, dan lain-lain) kerap hanya merupakan pertobatan emosional, tetapi tidak berakar mendalam pada sendi kehidupan berupa perbaikan perilaku. Ketika sedang menjalankan pertobatan (puasa) orang menjadi kelihatan sangat saleh, tetapi sesudah puasanya berakhir kesalehannya pun berakhir.

$>$ Iman individualis: Iman harus merupakan iman individual karena dihayati secara pribadi dan mendalam. Akan tetapi, tidak boleh dilupakan bahwa iman juga mempunyai segi sosial, yakni penghayatan iman bersama orang lain. Bahkan iman kita, kita warisi dari orang lain. Oleh karena itu, menjadi orang yang saleh saja, tetapi tidak peduli lingkungan sekitar, tidaklah cukup. Ada istilah yang bagus untuk menggambarkan prinsip ini, yakni Garam tidak berguna hanya untuk dirinya sendiri.

Ateisme praktis: Ateisme secara teoritis sekarang ini hampir lenyap. Orang yang memperjuangkan idiologi atheisme tinggal sedikit, tetapi orang yang mempraktekkan atheisme semakin banyak. Atheisme praktis adalah orang yang masih mengakui bahwa Tuhan itu ada (atau sekurang-kurangnya tidak pernah menyangkal keberadaannya) tetapi dalam hidupnya sama sekali tidak pernah melibatkan Tuhan, atau bahkan tidak pernah ada pemikiran mengenai Tuhan. Secara teoritis dia masih beragama, sekurang-kurangnya menurut Kartu Tanda Penduduk (KTP), tetapi segala tindakannya bertentangan dengan nilai-nilai keagamaan. Moralitasnya tidak didasarkan pada agama yang dianutnya. 


\section{Struktural:}

Di mana-mana terjadi diskriminasi dan penindasan terhadap kelompok minoritas baik oleh negara maupun oleh kelompok mayoritas yang mengemuka dalam bentuk pelarangan beribadah atau mendirikan tempat ibadah, perusakan tempat ibadah, dan lain-lain. Tidak ada jaminan kebasan beragama dalam kondisi ini.

Agama dijadikan alat legitimasi politik atau ekonomi. Legitimasi atas dasar agama baik dalam bidang ekonomi maupun politik merupakan legitimasi yang paling ampuh di Indonesia. Kehidupan politik dan ekonomi bukannya diresapi oleh semangat berdasarkan nilai-nilai agama tetapi justru menggunakan agama sebagai alat pendukungnya.

$>$ Politik identitas: identitas keagamaan digunakan sebagai kriteria dalam pola rekruitmen dan pola promosi internal para pengelola badan publik (Negara) maupun pasar (ekonomi). Para penguasa badan publik cenderung merekrut anggota dari agama yang sama dengan dirinya, bukan berdasarkan kompetensi yang dimilikinya.

\section{Kultural:}

$>\quad$ Relasi yang buruk antara umat beragama: minimnya komunikasi antar agama menyebabkan timbulnya kecurigaan terhadap kelompok lain, terlebih hubungan Kristen-Islam yang diwarnai oleh prasangka negatif. Mudah sekali timbul isu kristenisasi atau islamisasi.

Budaya kekerasan yang disulut sentiment keagamaan. Kecenderungan untuk menonjolkan klaim kebenaran tunggal pada diri umat beragama mendorong terjadinya sentiment keagamaan secara berlebihan. Agama-agama di Indonesia ada kecenderungan untuk membangun identitas komunitas secara berlebihan yang mengakibatkan munculnya sentiment keagamaan yang berujung pada terjadinya kekerasan atas nama agama.

$>$ Gaya hidup (keagamaan) yang dikuasai semangat pasar (konsumeris dan materialistik). Budaya modern menawarkan budaya instan (efektif dan efisien). Budaya instan mempengaruhi orang dalam segala sendi kehidupan, termasuk di dalam kehidupan beriman. Budaya instan menawarkan segala sesuatu terjadi dengan cepat dan praktis. Dalam budaya instan proses (laku) tidak dihargai. Tidak ada tempat bagi kegagalan, kesusahan 
dan penderitaan. Penghayatan iman instan : berdoa maunya cepat terkabul. Di dalam Gereja Katolik terlihat dalam gejala seperti misa maunya cepat, kotbah menarik, koor bagus, tetapi ia sendiri tidak terlibat apa-apa. Ke gereja sama dengan shoping, hanya mau menikmati tetapi tidak mau melibatkan diri. Budaya instan yang demikian ini menghasilkan orang yang tidak tahan banting.

\section{KESIMPULAN}

Pertanyaan mengenai mengapa Formalisme Hidup Beragama terjadi di tengah kehidupan masyarakat Purwokerto yang nampak religius yang menjadi pendorong bagi peneliti untuk melakukan penelitian ini memperoleh jawabannya sebagaimana diuraikan di atas. Penyebab formalisme agama itu dapat muncul dari internal ajaran agama, dari struktur sosial masyarakat dan dari budaya yang terbangun dalam masyarakat tersebut. Oleh karena itu, sebagai saran dari hasil penelitian ini, untuk mengatasi kecenderungan formalisme beragama tersebut juga harus menyentuh ketiga faktor penyebab di atas. Tidak cukup perbaikan kehidupan beragama hanya dibebankan kepada para pemimpin agama untuk memperbaiki pola pembinaan agama. Kalau ingin bahwa masyarakat Indonesia ini menghayati nilai-nilai keagamaan dalam kehidupannya secara benar harus ada perubahan dalam struktur dan kultur masyarakat. 


\section{DAFTAR PUSTAKA}

Berger, Peter L., 1990. The Sacred Canopy. New York, Anchor Books.

..dan Thomas Luckmann, 1991. The Social Construction of Reality; A Treastiaw in the Sociology of Knowledge. Bew York. Pinguin Books.

Geertz, Clifford, 1992. Tafsir Kebudayaan. Yogyakarta, Kanisius.

Keesing, Roger, M., 1981. Cultural Antropology. Paulis Press.

Konferensi Wali Gereja Indonesia, 2005. Hasil Sidang Agung Gereja Katolik Indonesia 2005.

Keuskupan Purwokerto, 2006. Hasil Musyawarah Pastoral Umat Katolik Keuskupan Purwokerto 2006.

Maslow, Abram, H., 2000. Agama, Nilai, Pengalaman Puncak (Terjemahan). Maumere. LPBAJ.

Rappaport, Roy A., 1999. Ritual and Religion in the Making Humanity. Cambridge, University Press.

Winangun, Wartaya, Y.W., 1990. Masyarakat Bebas Struktur. Yogyakarta, Kanisius. 